\title{
A 63-year-old man with hypomagnesaemia and seizures
}

\author{
Nirmalan Arulanantham, Mark Anderson, Neil Gittoes and Robin E Ferner
}

\section{Case presentation}

A 63-year-old lorry driver presented with 36 hours of recurrent vomiting. He had been having two loose motions a day for three months and had become increasingly lethargic. He was previously generally fit and well although a traumatic left arm radiculopathy had prevented him working for seven months. He was taking amlodipine for hypertension and simvastatin for primary prevention. He was also taking omeprazole $20 \mathrm{mg}$ twice daily, commenced four years previously, after an upper gastrointestinal endoscopy showed reflux oesophagitis and moderate duodenitis. Helicobacter pylori was not demonstrated. Discontinuation of the proton pump inhibitor (PPI) was followed by an episode of melaena, so his general practitioner recommenced omeprazole treatment. He was advised to continue on long-term PPI therapy. He drank up to 42 units of alcohol per week.

When examined on admission, blood pressure was 131/88 mmHg, pulse rate 101 beats per minute and cardiovascular, respiratory and abdominal examinations unremarkable. A few myoclonic jerks were noted on neurological examination. Random blood glucose concentration was $10.3 \mathrm{mmol} / \mathrm{l}$. Neutrophil count was elevated (at $15.5 \times 10^{9}$ per litre), serum concentrations of potassium 3.0 $\mathrm{mmol} / \mathrm{l}$, urea $8 \mathrm{mmol} / \mathrm{l}$, and creatinine $229 \mathrm{micromoles} / \mathrm{l}$ (normal range 44-133). Three hours after presentation he suffered a generalised seizure. Examination soon after showed a Glasgow Coma Scale of 3/15 improving to 11/15. Arterial blood gas analyses, taken on high flow oxygen, were as follows: $\mathrm{pH} 7.11, \mathrm{p}_{\mathrm{a}} \mathrm{O}_{2} 39.1 \mathrm{kPa}, \mathrm{p}_{\mathrm{a}} \mathrm{CO}_{2}$ $5.5 \mathrm{kPa}$, lactate $2.1 \mathrm{mmol} / \mathrm{l}$, base excess $-17.4 \mathrm{mEq} / \mathrm{l}$ and arterial bicarbonate concentration $12.3 \mathrm{mmol} / \mathrm{l}$. Further venous blood results became available: total calcium $1.90 \mathrm{mmol} / \mathrm{l}$ (normal range 2.2-2.6) and an unrecordably low serum magnesium concentration of $<0.10 \mathrm{mmol} / \mathrm{l}$ (normal range 0.7-1.0). Computed tomography head scan showed no intracranial lesion.

\section{What is the differential diagnosis and the most likely diagnosis?}

The possible causes of seizure included primary epilepsy or a seizure secondary to infection; a structural intracranial lesion,

Nirmalan Arulanantham, specialist registrar, clinical pharmacology and general medicine, Queen Elizabeth Hospital, Birmingham; honorary lecturer, Department of Clinical Pharmacology, University of Birmingham; Mark Anderson, consultant gastroenterologist, City Hospital, Birmingham; Neil Gittoes, consultant endocrinologist and divisional director, Queen Elizabeth Hospital, Birmingham; Robin E Ferner, consultant physician, City Hospital Birmingham; honorary professor of clinical pharmacology, University of Birmingham stroke or metabolic derangement and alcohol withdrawal. The raised white cell count supported the possibility of sepsis. When the severe hypomagnesaemia was found, this was sufficient to explain the seizure. PPIs, ${ }^{1,2}$ loose motions ${ }^{3}$ and alcohol consumption $^{3}$ have all been linked to hypomagnesaemia.

\section{What is the initial management?}

The patient was fluid resuscitated with up to seven litres of crystalloid per day, for the first two days, (Hartmann's and 0.9\% sodium chloride solution) as he was dehydrated and in pre-renal failure. Renal function returned to normal within 24 hours. A rapid intravenous infusion of magnesium sulphate $8 \mathrm{mmol}$ in $100 \mathrm{ml} \mathrm{5 \%}$ glucose was followed by a further infusion of $20 \mathrm{mmol}$ in $500 \mathrm{ml} 5 \%$ glucose over 12 hours with further similar infusions on Days 2 and 5. Calcium was replaced with $10 \mathrm{ml} \mathrm{10 \%} \mathrm{calcium}$ gluconate by bolus injection, followed by $10 \mathrm{ml} 10 \%$ calcium gluconate diluted in $250 \mathrm{ml} \mathrm{0.9 \%}$ sodium chloride infused over four hours. The latter was repeated on Day 3. The potassium deficit was corrected by infusing a total of $180 \mathrm{mmol}$ potassium chloride with the sodium chloride solution over 48 hours.

\section{Case progression}

Upper gastrointestinal endoscopy showed erosive gastritis with duodenitis and omeprazole $20 \mathrm{mg}$ twice daily was continued. Twenty-four hour urinary magnesium excretion was low at $0.9 \mathrm{mmol}$ (normal range 1.7-8.4). The patient was discharged two weeks after admission on omeprazole $20 \mathrm{mg}$ twice daily plus Helicobacter pylori eradication therapy, as magnesium concentrations had been stable for five days. He was readmitted after six weeks following a further seizure. Serum magnesium concentration had fallen to $0.25 \mathrm{mmol} / \mathrm{l}$. He received further intravenous magnesium sulphate and was discharged taking oral magnesium

\section{Key learning points}

- Hypomagnesaemia is a potentially fatal cause of seizures that is easily treated.

- Proton pump inhibitors (PPIs) are increasingly recognised to cause symptomatic hypomagnesaemia often after years of highlycompliant therapy.

- $\mathrm{H}_{2}$-receptor antagonists do not cause this adverse effect though they may not be effective in controlling symptoms.

- Hypomagnesaemia is common in patients who abuse alcohol.

- A serum magnesium of less than $0.4 \mathrm{mmol} / \mathrm{l}$ is severe enough to warrant intravenous correction. 


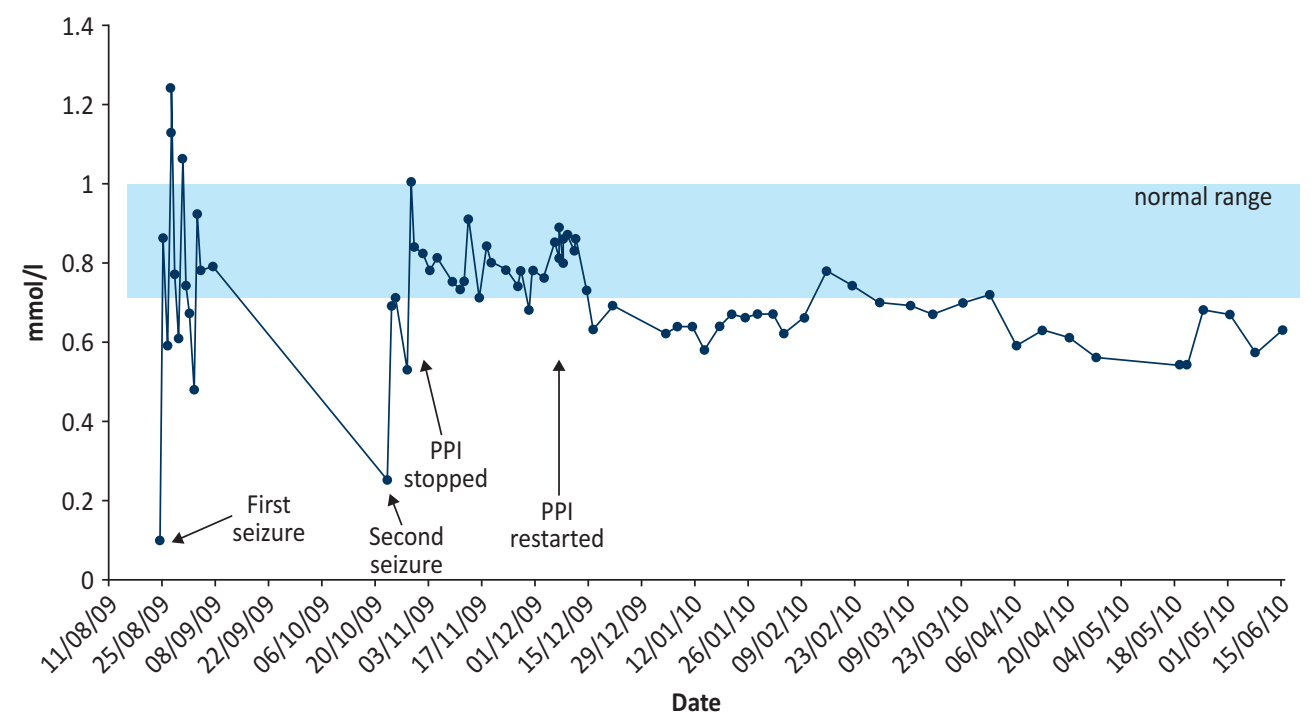

Fig 1. Serum magnesium concentration in the patient. $\mathrm{PPI}=$ proton pump inhibitor.

glycerophosphate $8 \mathrm{mmol}$ three times per day. Omeprazole was discontinued and ranitidine commenced as there was concern that PPIs were exacerbating the hypomagnesaemia (Fig 1); but as further endoscopy six weeks later showed Barrett's oesophagitis with significant duodenitis, another PPI, (lansoprazole $30 \mathrm{mg}$ ) was commenced.

Parathyroid hormone concentration was normal at $55 \mathrm{pg} / \mathrm{ml}$ (normal range 15-65), tissue transglutaminase antibodies, stool for ova, cysts and parasites, faecal elastase, colonoscopy, duodenal biopsies and barium follow through were all normal or negative. The patient developed abdominal pain when the dose of lansoprazole was reduced to $15 \mathrm{mg}$ daily, and went back to taking 30 mg. Reduction of the lansoprazole dose to $15 \mathrm{mg}$ eight months later caused abdominal pain so the dose was kept at $30 \mathrm{mg}$, despite concerns about PPI-induced hypomagnesaemia. Ranitidine aggravated diarrhoea. During nine months of follow up he required one 'top-up' infusion of magnesium despite continuing oral magnesium replacement. Codeine phosphate was ineffective at controlling diarrhoea but aluminium hydroxide worked.

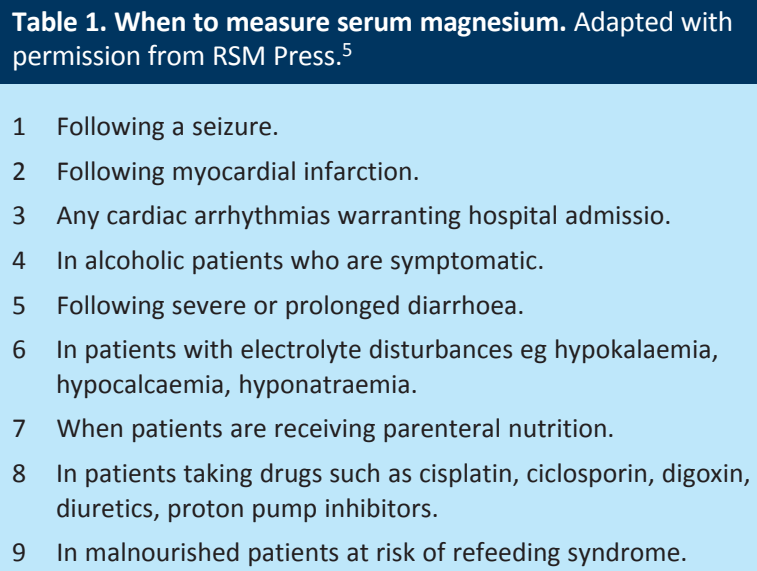

9 In malnourished patients at risk of refeeding syndrome.

\section{Discussion}

Magnesium deficiency is associated with weakness, tremor, apathy, psychosis, depression, seizures and cardiac arrhythmias. ${ }^{4}$ A serum magnesium concentration of less than $0.4 \mathrm{mmol} / \mathrm{l}$ is considered severe enough to warrant intravenous replacement. ${ }^{3} \mathrm{PPIs}$ are increasingly recognised to cause hypomagnesaemia, which is often only apparent after years of highly compliant therapy and which resolves on discontinuation of treatment. ${ }^{2}$ Rechallenge with an alternative PPI causes hypomagnesaemia making this phenomenon likely to be a class effect. ${ }^{2}$ The hypochlorhydria associated with PPIs reduces the solubility of magnesium salts, possibly causing less magnesium absorption. ${ }^{1} \mathrm{H}_{2}$-receptor antagonists, such as ranitidine, do not show this effect.

Serum magnesium concentration is controlled by intestinal absorption and urinary excretion. The transmembrane receptor protein channel, TRPM6, is important at low intraluminal concentrations of magnesium, allowing active transport against a gradient, both in the gut and kidney; TRPM7 channels may also play a role. Loss-of-function mutations (heterozygote) of the genes encoding these TRPM6 channels, combined with long-term PPI use may cause magnesium deficiency. ${ }^{2}$ Substituting ranitidine for PPI in this patient caused magnesium concentrations to rise but they fell again on recommencement. Hypomagnesaemia related to alcohol excess is thought to be due to tubular dysfunction that reverses on abstinence. ${ }^{3}$ This patient probably had several causes of hypomagnesaemia. The PPI is necessary to control his dyspepsia and oral magnesium replacement causes diarrhoea, making long-term management difficult. Table 1 lists those circumstances in which hypomagnesaemia should be considered. ${ }^{5}$

\section{Acknowledgements}

The authors are grateful to Christopher Anton and Sarah McDowell for reading through the draft and making helpful suggestions. 


\section{References}

1 Shabajee N, Lamb EJ, Sturgess I, Sumathipala RW. Omeprazole and refractory hypomagnesaemia. BMJ 2008;337:a425.

2 Mackay JD, Bladon PT. Hypomagnesaemia due to proton-pump inhibitor therapy: a clinical case series. QJM 2010;103:387-95.

3 Agus ZS. Hypomagnesemia. J Am Soc Nephrol 1999;10:1616-22.

4 Guidelines 2000 for cardiopulmonary resuscitation and emergency cardiovascular care. Part 8: advanced challenges in resuscitation: section 1: life-threatening electrolyte abnormalities. The American Heart Association in collaboration with the International Liaison Committee on Resuscitation. Circulation 2000;102(8 Suppl):I217-22.

5 Ryan MF. The role of magnesium in clinical biochemistry: an overview. Ann Clin Biochem 1991;28(Pt 1):19-26.

Address for correspondence: Dr N Arulanantham, Room 58G, Fifth Floor, Nuffield House, Queen

Elizabeth Hospital, Edgbaston, Birmingham B15 2TH.

Email: nirmalan.arulanantham@doctors.org.uk

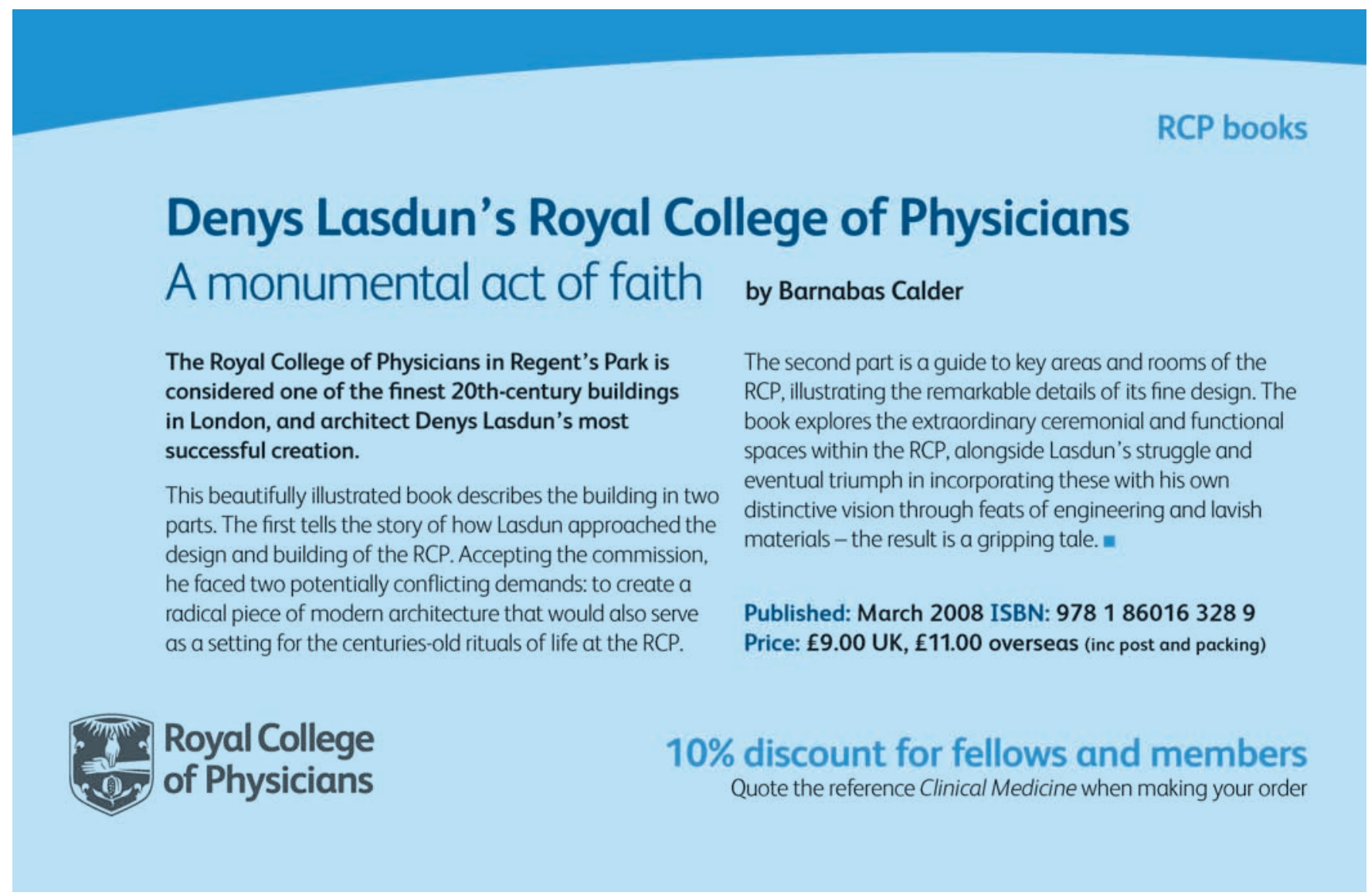

